\title{
Gastric perforation by a ventriculoperitoneal shunt in an adult
}

Yu-Hao Chen, MD, Cheng-Ta Hsieh, MD, Jui-Ming Sun, MD, Sio-Iong Chang, MD, MS.

\begin{abstract}
عملية التحويلة البطينية البريتونية (VP) هي إجراء جراحة

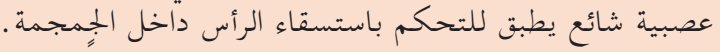

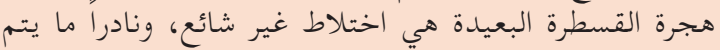

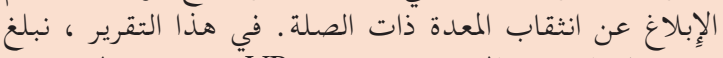

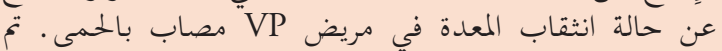

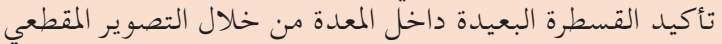

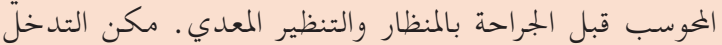

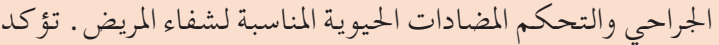

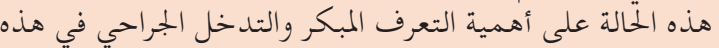
المضاعفات النادرة المتعلقة بإجراء التحمية التحفيلة المبحر والتح
\end{abstract}

Ventriculoperitoneal (VP) shunt operation is a common neurosurgical procedure applied for managing intracranial hydrocephalus. Migration of a distal catheter is an uncommon complication, and related gastric perforation is rarely reported. Herein, we report the case of gastric perforation in a patient with VP shunt who presented with fever. The distal catheter within the stomach was confirmed by preoperative computed tomographic scan of abdomen and gastric endoscopy. Surgical intervention and appropriate antibiotics management enabled patient recovery. This case emphasizes the importance of early recognition and surgical intervention in this rare complication related to the shunt procedure.

Neurosciences 2020; Vol. 25 (2): 144-147 doi: 10.17712/nsj.2020.2.20190118

From the Section of Neurosurgery (Chen, Sun), Department of Surgery, Chia-Yi Christian Hospital, Health Sciences and Management (Chen), Chung-Jen Junior College of Nursing, Chia-Yi, Division of Neurological Surgery (Hsieh), Department of Surgery, Sijhih Cathay General Hospital, Department of Medicine (Hsieh), School of Medicine, Fu Jen Catholic University, Department of Neurological Surgery (Hsieh, Sun), Tri-Service General Hospital, National Defense Medical Center, Taipei, Department of Biotechnology (Sun), Asia University, Taichung, and from the Department of Neurosurgery (Chang), YongHe Cardinal Tien Hosipital, New Taipei, Taiwan.

Received 9th December 2019. Accepted 23th January 2020.

Address correspondence and reprint request to: Dr. Sio-Iong Chang, Department of Neurosurgery, YongHe Cardinal Tien Hospital, Taipei, Taiwan.E-mail:brain23.tw@yahoo.com.tw

ORCID ID: https://orcid.org/0000-0003-4606-6315
Tentriculoperitoneal (VP) shunt (VPS) operation is a common neurosurgical procedure to treat hydrocephalus related to head trauma, vascular malformation, infection, or neoplasm. ${ }^{1,2}$ Several complications associated with the VP shunt, including obstructive, kinking, infection, disconnection, pseudocyst formation, ascites, or migration, are well documented. ${ }^{3,4}$ Although the migration of peritoneal catheter can involve any intraabdominal organ, gastric perforation by VP shunt is rarely described; only approximately 20 cases have been reported thus far. ${ }^{2,5}$ Herein, we report the case of patient who underwent VPS and presented with fever thereafter. The gastric perforation by the distal catheter of the shunt was confirmed through computed tomography (CT) and gastric endoscopy. Early recognition and surgical intervention are the keystones to manage this complication. The objective of presenting this case is that early recognition and surgical intervention are the keystones to manage this complication.

Case Report. Patient information. The informed consent was obtained from the patient for the case report. The timeline for this case report was summarized in Table 1. A 54-year-old woman with a history of communicating hydrocephalus resulting from meningitis had undergone VPS 10 years before admission to the hospital. This first shunt was placed in a different hospital with unknown shunt type. The peritoneal tube (silicon) was placed via open minilaparotomy. After she developed meningitis, her daily life had become dependent on the nursing care unit. In the current case, she presented to the Emergency Department with low-grade fever which had persisted over 5 days.

Disclosure. The authors declare no conflicting interests, support or funding from any drug company. 


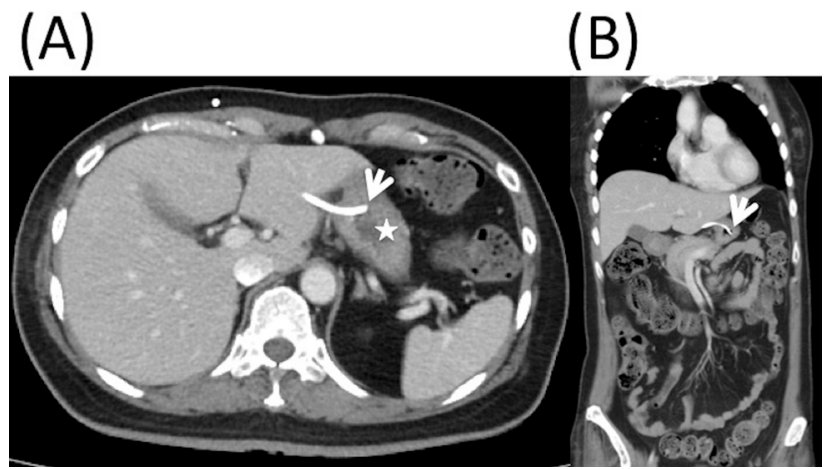

Figure 1 - Computed tomography images of the abdomen showing the distal catheter migration into the stomach: axial view A) and coronal view, B) (white arrow: perforation site; white asterisk: stomach).

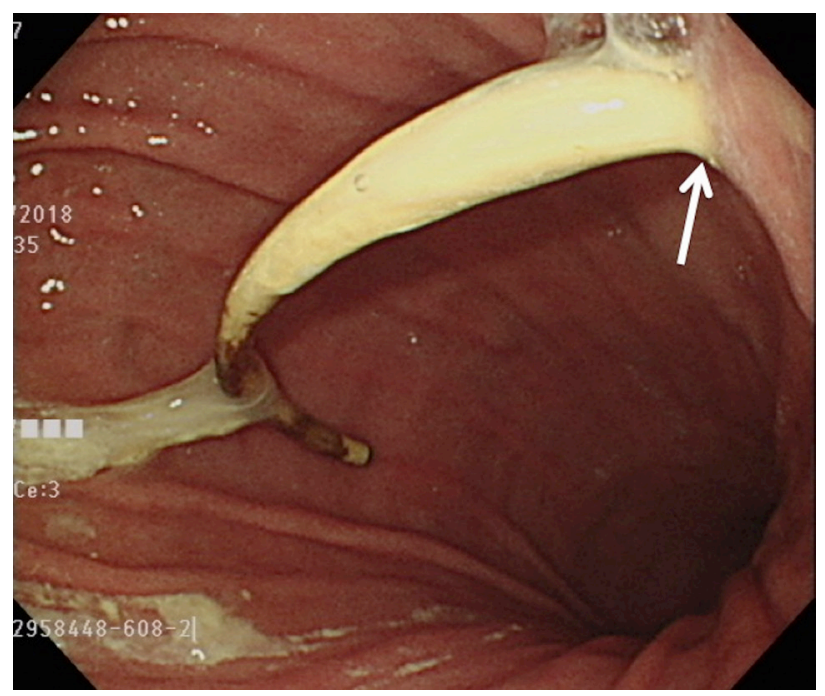

Figure 2 - Gastric endoscopy revealing the distal catheter of the shunt perforating the stomach (white arrow: perforation site).

Clinicalfindings. At admission, physical examination revealed that her body temperature was $38^{\circ} \mathrm{C}$ and respiratory rate was 20 breaths/min. The patient appeared to have a drowsy consciousness. Kernig's sign and Brudzinski's sign were absent. The reservoir of the shunt at the right frontal region was nonfunctional with delayed filling. No any swelling or redness around the distal shunt tube or pseudomeningocele around the valve was found. The laboratory examination revealed a white blood cell count of $11970 / \mu \mathrm{L}$ and C-reactive protein level of $1.27 \mathrm{mg} / \mathrm{dL}$.

Diagnostic assessment. Brain CT without contrast revealed increased hydrocephalus and an optimal position of the intracranial catheter in the right frontal horn of the lateral ventricle. In the revision surgery, reservoir was replaced initially because the proximal shunt tube was stuck in the brain. No shunt-o-gram study was performed before operation. The glucose and protein level in the cerebrospinal fluid (CSF) were 21 $\mathrm{mg} / \mathrm{dl}$ and $556 \mathrm{mg} / \mathrm{dl}$, respectively. The bacterial culture from the intraoperative CSF revealed an infection of oxacillin-sensitive Staphylococcus aureus. However, fever was persistent, and the CT images of the abdomen demonstrated that the peritoneal catheter was retained in the stomach (Figure 1).

Therapeutic intervention. A gastroenterologist was consulted for panendoscopy, and the resulting images confirmed the presence of peritoneal catheter penetrating the stomach (Figure 2). Furthermore, the shunt migration into the stomach was associated with the infection of the central nervous system (CNS). The patient underwent surgery for the removal of previous VPS following the insertion of the external ventricular drainage (Wellong instruments Co. Ltd). The removal of the peritoneal catheter and gastrorrhaphy were performed through midline open laparotomy by a general surgeon. The bacterial cultures of these tubes revealed the infection of Stenotrophomonas and Entercoccus faecium. The CSF culture was carried out every week and the last 3 CSF cultures before final shunt surgery were negative. This infection was controlled after 6-weeks ceftriaxone and vancomycin therapy. Before revision shunt surgery, the CSF glucose and protein were $55 \mathrm{mg} / \mathrm{dl}$ and $36 \mathrm{mg} /$ $\mathrm{dl}$, respectively. The CSF culture revealed no bacterial growth. Then, the VPS (Wellong instruments Co. Ltd) with burr hole type was performed through left frontal horn of lateral ventricle to left abdomen. The peritoneal shunt was inserted via mini-laparotomy.

Follow-up and outcomes. The patient recovered satisfactorily for post-operatively 1 -year follow-up.

Discussion. The VPS is a surgical procedure to divert the abnormal flow or impaired absorption of cerebrospinal fluid into the peritoneal cavity for treating the intracranial hydrocephalus. ${ }^{2-4}$ The migration of peritoneal catheter is a rare condition, and the incidence is approximately 1 in 1000 patients who have undergone the VPS. ${ }^{2}$ Based on the anatomical analysis, Alloch et $\mathrm{al}^{4}$ classified the migration of the distal catheter into 3 patterns: internal, external, and compound. The internal migration mostly occurs in adults and may involve heart, pleural cavity, abdominal wall, urinary bladder, uterine, vagina, scrotum, or gastrointestinal tract. ${ }^{2,4}$ However, the gastrointestinal tract perforation is rare, and the overall incidence at the rate of $0.01 \%$ to $1 \%$ is more common in children than adults. ${ }^{1,4,5}$ Furthermore, 
Table 1 - The timeline for the presented case.

\begin{tabular}{|c|c|c|c|}
\hline Dates & \multicolumn{3}{|c|}{ Relevant past medical history and interventions } \\
\hline & \multicolumn{3}{|c|}{$\begin{array}{l}\text { A past history of communicating hydrocephalus resulting from meningitis had undergone VPS } 10 \text { years before admission } \\
\text { to the hospital. This first shunt was placed in a different hospital with unknown shunt type. The peritoneal tube (silicon) } \\
\text { was placed via open mini-laparotomy. }\end{array}$} \\
\hline Date & $\begin{array}{c}\text { Summaries from Initial and } \\
\text { Follow-up Visits }\end{array}$ & Diagnostic Testing (including dates) & Interventions \\
\hline $2018 / 8 / 2$ & 5-day fever & $\begin{array}{l}\text { - White blood cell count of } 11970 / \mu \mathrm{L} \\
\text { and C-reactive protein level of } 1.27 \mathrm{mg} / \mathrm{dL} \\
(2018 / 8 / 2) \\
\text { - Computed tomographic (CT) scan of brain } \\
\text { revealed increased hydrocephalus }(2018 / 8 / 2) \\
\text { - The glucose and protein level in the } \\
\text { cerebrospinal fluid (CSF) were } 21 \mathrm{mg} / \mathrm{dl} \text { and } \\
556 \mathrm{mg} / \mathrm{dl}(2018 / 8 / 14) \\
\text { - The bacterial culture from the } \\
\text { intraoperative CSF revealed an infection } \\
\text { of oxacillin-sensitive Staphylococcus aureus } \\
\text { (2018/8/14) }\end{array}$ & $\begin{array}{l}\text { - Start cefmetazole } \\
\text { treatment }(2018 / 8 / 2) \\
\text { - Revision surgery with } \\
\text { replacement of reservoir } \\
\quad(2018 / 8 / 14)\end{array}$ \\
\hline $2018 / 8 / 15$ & Persistent fever & $\begin{array}{l}\text { - CT images of the abdomen demonstrated } \\
\text { that the peritoneal catheter was retained in } \\
\text { the stomach }(2018 / 8 / 15) \\
\text { - Panendoscopy confirmed the presence of } \\
\text { peritoneal catheter penetrating the stomach } \\
\text { (2018/8/17) } \\
\text { - The bacterial cultures of these tubes } \\
\text { revealed the infection of Stenotrophomonas } \\
\text { and Entercoccus faecium. }(2018 / 8 / 24)\end{array}$ & $\begin{array}{l}\text { - Start teicoplanin and } \\
\text { cefotaxime treatment } \\
(2018 / 8 / 19) \\
\text { - Surgery for the removal } \\
\text { of previous VPS following } \\
\text { the insertion of the external } \\
\text { ventricular drainage. The } \\
\text { removal of the peritoneal } \\
\text { catheter and gastrorrhaphy } \\
\text { were performed through } \\
\text { midline open laparotomy } \\
\text { by a general surgeon. } \\
\quad(2018 / 8 / 24) \\
\text { - Vancomycin and } \\
\text { ceftriaxone treatment } \\
\text { (2018/8/24 2018/10/9) }\end{array}$ \\
\hline $2018 / 10 / 1$ & Hydrocephalus without fever & $\begin{array}{l}\text { - CSF culture revealed no bacterial growth. } \\
\qquad(2018 / 9 / 24) \\
\text { - CSF glucose and protein were } 55 \mathrm{mg} / \mathrm{dl} \\
\text { and } 36 \mathrm{mg} / \mathrm{dl} \text {, respectively. }(2018 / 10 / 1)\end{array}$ & $\begin{array}{l}\text { The revision of VPS with burr } \\
\text { hole type was performed through } \\
\text { left frontal horn of lateral } \\
\text { ventricle to left abdomen. The } \\
\text { peritoneal shunt was inserted via } \\
\text { mini-laparotomy. }(2018 / 10 / 1)\end{array}$ \\
\hline $2018 / 10 / 9$ & $\begin{array}{l}\text { Discharge without fever; shunt } \\
\text { was functional }\end{array}$ & & \\
\hline 2019/11/11 & No fever; shunt was functional & & \\
\hline
\end{tabular}

the colon is the most commonly reported site, and only 21 patients with gastric perforation by a VP shunt have been reported in 2 comprehensive literature reviews. ${ }^{2,6}$

The etiology of gastric perforation by a VP shunt is unclear. Several risk factors have been considered, such as the long intraabdominal end of catheter, sharp catheter tip, bio-reactivity of the shunt component, stiff consistency of the shunt, allergy of silicon, or barium coating of the shunt. ${ }^{7}$ Despite the iatrogenic gastric perforation during VPS, mechanisms such as the formation of local inflammation or fibrosis between the rigidity of the catheter and less motility of the organ, which potentially contribute to gastric perforation after VPS, have been hypothesized. ${ }^{2,4,5}$ Furthermore, the ulceration and eventual perforation develops through the "pushing effect" related to the repeated pulsatile cerebrospinal fluid flow when the site of distal catheter adheres to the stomach wall. ${ }^{5}$ Because our patient had 
been nonambulatory, the lack of active movement may have increased the risk of shunt migration around the stomach and promoted further ulceration and perforation of the stomach.

The period from shunt installation to gastric perforation can vary from several weeks to many years. ${ }^{8,9}$ Patients with shunt migration into the stomach may present with fever, abdominal pain, vomiting, diarrhea, lethargy, shunt malfunction, abscess, peritonitis, or gastric bleeding. ${ }^{5,8-10}$ Notably, patients with an asymptomatic presentation were incidentally found by gastric endoscopy. ${ }^{1,6}$ However, the most cases of peroral extrusion of the distal catheter, primarily occurring in children, originate from gastric perforation. ${ }^{5}$

The shunt tube may appear radiolucent in plain radiography, and hence, abdomen and pelvis CT is considered for the initial investigation to identify the perforation site and the associated inflammation. ${ }^{2,4}$ Endoscopy is an effective alternative method to confirm the specific location and characterize the perforation and the migrated catheter. ${ }^{1}$ By contrast, radiopaque material-like contrast may be injected into the reservoir to visualize the pathway of the distal catheter. ${ }^{9}$ Escherichia coli is the most common pathogen that induces the intraabdominal or retrograde CNS infection. ${ }^{6}$ Therefore, migration of the distal shunt with gastrointestinal tract perforation should be considered when the patients with a VP shunt present with CNS infection of enteric gram-negative organisms. ${ }^{6,9}$

The overall mortality rate after perforation is approximately $18 \%$, and it primarily involves CNS infections, such as meningitis, ventriculitis, and encephalitis. ${ }^{1,2,6}$ Early recognition of this complication is crucial, and surgical intervention is the gold standard treatment for patients with gastric perforation due to distal catheter migration. 5 Subsequently, the removal of the catheter from the perforated stomach wall, followed by direct suture of the ruptured stomach wall, is recommended. The distal externalization of the distal catheter following the revision of the VP is recommended to manage the hydrocephalus. During the infection period, appropriate antibiotic therapy is also a vital component of the management of this complication. In patient's perspective, shunt-associated infection should be kept in mind when fever or any abdominal discomfort occurs following the VP shunt surgery for the hydrocephalus.

In conclusion, the migration of the distal catheter into the stomach is a rare complication, particularly when VPS patients present with fever or other intra-abdominal discomforts. Early recognition and surgical intervention are the keystones to manage this complication.

\section{References}

1. Cohen-Addad DI, Hewitt K, Bell D. A ventriculoperitoneal shunt incidentally found in the stomach. Radiol Case Rep 2018; 13: 1159-1162.

2. Harischandra LS, Sharma A, Chatterjee S. Shunt migration in ventriculoperitoneal shunting: A comprehensive review of literature. Neurol India 2019; 67: 85-99.

3. Hsieh CT, Pai CC, Tsai TH, Chiang YH, Su YH. Hepatic cerebrospinal fluid pseudocyst: a case report and review of the literature. Neurol India 2006; 54: 86-88.

4. Allouh MZ, Al Barbarawi MM, Asfour HA, Said RS. Migration of the distal catheter of the ventriculoperitoneal shunt in hydrocephalus: A Comprehensive Analytical Review from an Anatomical Perspective. Clin Anat 2017; 30: 821-830.

5. Al Fauzi A, Suryaningtyas W, Wahyuhadi J, Parenrengi MA, Turchan A, Wijaya MC, et al. Upward migration and peroral extrusion of a peritoneal shunt catheter: Case report and review of the literature. Surg Neurol Int 2017; 8: 178.

6. Yousfi MM, Jackson NS, Abbas M, Zimmerman RS, Fleischer DE. Bowel perforation complicating ventriculoperitoneal shunt: creport and review. Gastrointest Endosc 2003; 58: 144-148.

7. Ezzat AAM, Soliman MAR, Hasanain AA, Thabit MA, Elshitany H, Kandel H, et al. Migration of the Distal Catheter of Ventriculoperitoneal Shunts in Pediatric Age Group: Case Series. World Neurosurg 2018; 119: e131-e137.

8. Cheng JY, Lo WC, Liang HH, Kun IH. Migration of ventriculoperitoneal shunt into the stomach, presenting with gastric bleeding. Acta Neurochir (Wien) 2007; 149: 1269-1270.

9. Masuoka J, Mineta T, Kohata T, Tabuchi K. Peritoneal shunt tube migration into the stomach--case report. Neurol Med Chir (Tokyo) 2005; 45: 543-546.

10. Ghritlaharey RK. Review of the Management of Peroral Extrusion of Ventriculoperitoneal Shunt Catheter. J Clin Diagn Res 2016; 10: PE01-PE06. 